\title{
MAKING THE MIDDLE CLASSES ON SHIFTING GROUND? RESIDENTIAL STATUS, PERFORMATIVITY AND MIDDLE-CLASS SUBJECTIVITIES IN CONTEMPORARY LONDON
}

Michaela Benson and Emma Jackson

This paper argues that shifts in access to housing - both in relation to rental and ownership - disrupt middle-class reproduction in ways that fundamentally influence class formation. While property ownership has had a long association with middle-class identities, status and distinction, an increasingly competitive rental market alongside inflated property prices has impacted on expectations and anxieties over housing futures. In this paper, we consider two key questions: (1) What happens to middle-class identities under the conditions of this wider structural change? (2) How do the middle classes variously manoeuvre within this? Drawing on empirical research conducted in London, we demonstrate that becoming an owner-occupier may be fractured along lines of class but also along the axes of age, wealth and timing, particularly as this relates to the housing market. It builds on understandings of residential status and place as central to the formation of class, orienting this around the recognition of both people and place as mutable, emphasising that changing economic and social processes generate new class positionalities and strategies for class reproduction. We argue that these processes are writ large in practices of belonging and claims to place, with wider repercussions within the urban landscape.

\section{Keywords}

Middle classes, classed subjectivities, London, housing crisis, social reproduction 


\section{Introduction}

In June 2014, television property guru Kirsty Allsop stated in a newspaper interview: “I don't have a girl, but if I did I'd be saying 'Darling, do you know what? Don't go to university. Start work straight after school, stay at home, save up your deposit - I'll help you, let's get you into a flat. And then we can find you a nice boyfriend and you can have a baby by the time you're 27" (Gordon, 2014: npg.). While the media furore and public discussion following the publication of this news piece centred on the gendered aspects of these comments, as researchers who study the middle classes what caught our attention was the emphasis on property, rather than education, as a means of social reproduction. This statement hints towards changing concerns around property ownership, particularly concerns over the next generation of young middle-class people, mirroring interview data from our recent research on the middle classes (Bacqué et al. 2015). Simply put, for Allsopp ownership of a flat trumps education as a route to security.

In this paper we examine middle-class negotiations through the field of housing in London, a globalised housing market that is becoming increasingly unaffordable. It sheds light on a small part of a landscape characterised by changes at both ends of the spectrum: the inflation of the super-prime housing market resulting from the investment of global financial capital (Burrows et al., in press) and rises in eviction and displacement at the other end (Dorling 2015). These are not discrete stories but are interconnected both in terms of urban processes (e.g. regeneration, gentrification, privatisation) and their knock on effects on changing patterns of housing tenure. 
We ask what happens to middle-class identities as these urban processes unfold? What strategies do middle-class households use to navigate this changing context? It is urgent and timely to revisit these questions in light of the rapid escalation of property and rental values and consequent concerns over the affordability of housing and shelter, issues that disproportionately impact on younger subjects. In this way, the article develops the conversation initiated by Watt (2005) in relation to the economically marginal middle classes to consider the broader middle classes. As Tyler (2015) has argued, the increasingly precarious conditions brought on by neoliberalism impact not only on the working classes, but also on some members of the middle classes; such impacts urgently require empirically driven sociological research. If housing and residence are the grounds on which middle-class identities are formed, what happens under conditions of unequal access to home ownership among the middle classes?

We argue that the changing contexts of housing in London provide opportunities for some to shore up their middle-class identities through the property market, while others find the articulation of these constrained by precisely the same processes. The changing market exacerbates inequalities within the middle classes in complex ways that on the surface might appear to be about age and/or generation, but dig a little deeper and tenure emerges as both a symptom and cause. On these shifting grounds how are housing navigated and middle-class identities reconstituted?

In laying out the context of the London housing market, we start the article with a discussion of the relationships between middle-class formation, property ownership and housing. This sets the stage for our argument that the changing nature of the housing market makes well-established routes to middle-class reproduction through 
property assets less certain; wider anxieties about housing, with a particular inflection on generation-housing children-were a repeated pattern within the research. Turning to Peckham-one neighbourhood in our comparative research project on the middle classes-we explore housing narratives in depth to unravel how the relationship between property ownership and classed positions is variously articulated in relation to age and stake in London's housing economy, highlighting how in some cases this might include increasingly precarious stakes.

\section{Housing, class analysis and the middle classes}

Muir and McKee (2013) have argued that within housing studies, it is increasing important that class analysis is used to interpret widening inequalities within housing. We build on this in order to argue that widening inequalities within housing-including those within the middle classes-need to be brought into class analysis. As Hamnett $(1995,1998)$ has argued, home-ownership operates in a variety of ways to support and reinforce class formation and reproduction. This understanding draws both on home ownership as consumption, its significance characterized by its relationship to status and distinction (Bourdieu 1984; Hamnett 1995), but also by its exchange value (Forrest and Murie 1980), whereby it offers the possibility of accumulation and investment (Saunders 1978). Although housing is not the only factor influencing this, the current context and its implications for changing access to housing in London needs to be examined in relation to (middle-)class formation.

As we demonstrate this can be read through how respondents in the reported research operate and rationalize the situations in which they find themselves, particularly in articulations of social class and the expectations of young middle-class people who grew 
up with the expectation of following the footsteps of their parents into home ownership. And yet, following Allen and Roberts (2016), we remain critical of the argument that sees rising inequality fractured by generation. Simply put, access to home ownership is structured in ways that cannot be explained purely by a generational logic; differences in tenure both signal rising housing inequalities among the middle classes and produce them.

Our exploration here examines the contemporary dynamics of housing in London as these are felt and experienced across generations of middle-class households. It considers how differential access to home ownership, in its temporal and spatial dimensions, impacts on people's sense of themselves as middle class and their hopes and fears for the future. In this way, we contribute to the increasing recognition within class analysis that contemporary social and economic trasformations are paralleled by changes within class structure (Bradley 2014; Dorling 2014; Savage et al. 2013, 2014).

The paper therefore intervenes in discussions on how middle-class identities are (re)constituted and (re)produced on ever-shifting grounds and more specifically, the significance of housing to these processes. It complicates narratives about the relationship between residential status, housing tenure and middle-class formation. It examines how the London housing economy is variously experienced, manoeuvred and negotiated by the middle classes: the 'winners' reluctant and ambivalent about the increased values of their homes; and the renters facing the prospect of ever-increasing rents and limited access to home ownership.

\section{Performativity: making value on shifting ground}


Our critical focus on how interactions within the housing economy are narrated and performatively constructed develops our previous work on the relationship between middle-class residential practices, place-making and belonging (Benson and Jackson 2013; Jackson and Benson 2014; Benson 2014). In this way, we highlight how the middle classes in London variously make sense of and seek legitimacy for their engagements within the housing economy.

The middle classes in and through (London's) housing economy

In the second half of the twentieth century, homeownership in Britain expanded across social classes (Saunders 1990). The middle classes were the prime beneficiary of house price inflation and forms of intergenerational wealth transfer based on housing assets (Forrest et al. 1990; Bone and O’Reilly 2010). As Savage et al. (1992; see also Savage and Butler 1995) outline, such changes to the housing economy were concurrent with the rise of an emergent social collectivity, a middle-class fraction whose position was characterized by their accumulation of property assets. This asset-based approach-a development of Bourdieu's (1984) approach to class as made through the possession of different capitals-foregrounded the dynamics of class formation, the contingency of such processes on social and economic contexts, and the role of the cultural and social within this alongside economic resources. Notably, within this schema, property is identified as a key asset or resource in the formation of the middle classes. Rather than a stable class formation with clear frontiers, this understanding of the middle classes rests on a conceptualization of class formation that recognizes the extent to which these are made (and remade) in and through material and symbolic struggles (Bourdieu 1984; Wacquant 1991; Skeggs 1997, 2004). 
As our introduction to this article outlines, while property ownership has become a cultural expectation-communicated through media ad infinitum-and is one marker by which middle-class parents understand social reproduction, this is paired with the realization that rapidly spiralling property prices in the capital place home ownership further out of reach of many young people today. Rising housing inequality (Barker 2014; Dorling 2014) is drawn along lines not only of those with and without financial backing, but also fractured along lines of generational differences in access, impacting disproportionately on younger generations (McKee 2012; Pennington et al. 2012). This generational argument chimes with wider concerns about the future of the middle classes; the fear of falling first identified by Ehrenreich (1990), translated to the consideration of the apparent decline in living standards experienced by younger generations (Chauvel 2006; Maurin 2009; Savage et al. 2015). Understanding how class intersects with age, a significant lacuna within class analysis (Savage et al. 2015), is now of timely and urgent importance.

Further, this paper calls into question understandings of middle-class formation built on the observation of a population experiencing high levels of social mobility, riding the wave of social and economic transformations that brought in their wake significant changes in access to higher education, rises in white collar employment and home ownership (see for example Savage et al. 1992; Savage and Butler 1995). Our claim here is blunt: the experiences of this previous generation should be considered as idiosyncratic, neither reflected in the experience of those who came before or after them. However, the conceptual tools and framings that identified these new middleclass formations that highlight the role of assets and resources within the accumulation 
of capitals may be usefully put to work as we think through class formation under contemporary conditions (Atkinson et al. 2012; Atkinson 2015).

Given the significance of home ownership to middle-class formation among a previous generation, it is timely to question what happens to class formation across generations under the current conditions of London's housing economy.

\section{Class formation in and through the narration of housing practices}

Rather than predict the demise of the middle classes linked to the changing housing fortunes, we explore instead-through our dual focus on subjectivity and performativity-how the presentation of housing struggles becomes part and parcel of the discursive practices in action through which middle-class subjectivities are formed and produced in everyday lives.

The argument we present in this paper builds on an understanding of class that draws together Bourdieusian and feminist perspectives. Class-as a concept-names inequality (Tyler 2015; Savage 2015); it is inherently relational, a project that classifies others through judgments of value and taste, and simultaneously locates the classifying subject (Bourdieu 1984; Skeggs 2004). It is tied to material and economic relations, a symbolic and cultural process (Bourdieu 1984; Skeggs 1997, 2004). Rather than the categories of measurement at play in how class is conceived in relation to stratification, we conceptualize class as continually (re)produced, an ongoing process whereby class positions are made, told, and performed in and through struggles over power and authority (Bradley 1995, 2014; Skeggs, 1997, 2004, 2015; Crompton 2008). As Skeggs (2004) highlights, the middle-class self is (re)produced in everyday lives precisely 
through these struggles, value and personhood claimed performatively as 'middle-class selves attempt to retain legitimacy and authority for the choices they make and resources they use ... But this authority is fragile and has to be continually asserted' (ibid. 2004: 140; emphasis added).

London's housing economy and the (relative) struggles of young people-and attendant anxieties about social reproduction-are one current and highly visible locus of such struggles for value and personhood. Elsewhere, we have used performativityfollowing Judith Butler's $(1990,1993)$ focus on this as the repetition of acts and discursive practice in the production of social phenomena and Skeggs' (2004) application of this to the (continual) generation of classed subjectivities-to describe the deeply entangled processes of place-making and middle-class belonging (Benson and Jackson 2013; Benson 2014). As we have argued, at the time of the research Peckham was a location marginal to middle-class imaginings of London, but was being actively remade in the image of its middle-class residents. This was an active process through which some of these residents sought recognition for their ability to live in a socially and ethnically diverse part of London not on the 'middle-class map' while also supporting the development of a (white) middle-class infrastructure to support middleclass living in the area. Through these practices symbolic value and legitimacy are claimed. Implicit to this process was property ownership; symbolic investment in neighbourhoods through claims to belonging went hand-in-hand with a concern over property prices and exchange value.

The current paper maps how different stakes in this localised housing economy are narrated and experienced, and with what consequences for the production of middle- 
class identities. The repeated and reiterative narration of negotiations in relation to housing-triumphs, anxieties, and ambivalences-reveal differences in what people have, how they make sense of this and how they cope. This is about more than the fragmentation of the middle classes; tracing the housing narratives of long-term owneroccupiers, recent homeowners in the area and young renters demonstrate the various ways in which value is claimed and made, the legitimacy of actions rehearsed, performed and authenticated. The empirical research presented below, thus demonstrates the ways in which middle-class positions are claimed and made precisely through discourses about (a) current housing struggles, (b) housing futures and (c) the identification of structural constraints on the ability to live up to housing expectations.

\section{Methods}

The research discussed in this paper is part of the comparative research project "The Middle Classes in the City: Social Mix or just 'People Like Us' (Bacque et al. 2015). A Comparison of Paris and London'. The study examined the middle-class residents living in five different types of neighbourhood across each of these cities-gentrified, gentrifying, gated community, suburban and exurban-and their relationships to and practices of place. The research also examined classed identity formation, hopes and plans for the future and residential trajectories of middle-class people.

In total, we conducted 171 interviews with middle-class residents in London, spread equally across the five neighbourhoods. These were complemented with five interviews with key individuals (these included councillors, local business-owners, heads of local associations) in each neighbourhood. Walking tours of each neighbourhood led us to select down to the level of particular streets. We then mailed letters calling for 
participation to all addresses in those streets. Respondents were, therefore in part, selfselecting as middle class, contacting us if they wanted to take part. However, we managed to get a good mix of respondents in terms of gender and age, although this cannot be taken to be representative. Importantly, the sample in Peckham spanned differences in tenure and age, whereas in other areas responses tended to be skewed towards various fractions of the middle classes.

Interviews were semi-structured, incorporating themes such as residential choices and trajectories, social relations, use of public services and local amenities, political engagements, and relationship to place. We used an inductive process to design a coding structure, deriving our categories from the data. We tested these against the French data and refined the categories further. Although we used NVivo software to organize data thematically, the process of analysis has involved moving between these NVivo 'nodes' and full transcripts to ensure that the richness of transcripts is not lost. In this paper we have chosen to use longer representative quotes, rather than bundles of shorter quotations, in order to preserve the richness of the data, but also to maintain the sense of the ambivalence with which many of the respondents addressed their engagements with the housing economy.

We began our research in 2010, shortly after the Coalition government came to power and at a time when the financial crisis was having an impact. Thus the interviews took place against a background of announcements of public sector cuts and financial insecurity. In the UK, the crisis brought with it fears of a property crash, which in most parts of the country were realized. However, the effect on London's property market has not been as marked. While to begin with the outcome of the credit crunch on 
London's property market was uncertain (Greater London Authority 2008), there is no doubt that not only did this market survive the crisis, the value of properties in the capital continued to rise. ${ }^{1}$

\section{Paving the Way ${ }^{2}$}

For many people access to home ownership in Britain can no longer be taken for granted (Bone and O'Reilly 2010; Marshall and Smith 2016), the result of a range of factors including restrictions on mortgage lending; increased demand for housing; high property and land prices; and inadequate supply (Barker 2004; Kennett et al. 2013). Between 2001 and 2011, there was a London-wide decrease in ownership from 59.9 per cent to 49.9 per cent, while the private rental market increased from 15.3 per cent to 26 per cent (Greater London Authority, 2014). House prices in London increased at rates that substantially exceeded the increases in other parts of the United Kingdom; while rising rental values and insecurity of tenure in the private rental sector further delay the trajectory of people into home ownership.

Peckham is located in the London Borough of Southwark, an area characterised by social and ethnic mix (54.2 per cent white, 26.9 per cent Black African, Caribbean, Black British) with a multi-ethnic and bustling centre. House prices across Peckham have increased dramatically, with Illustreets (Timita 2014) reporting an increase of 79.9 per cent over ten years (2004-2013), a rate of increase that exceeds the average rise across London for the same time period. As well as being embroiled in the London-wide contexts of an over-heated housing market, and the Southwark context of the sell-off and demolition of social housing (Lees et al. 2014), the social and material fabric of 
Peckham are also being effected by other substantial infrastructural changes, most notably, the arrival of the East London line in 2012.

At the time of the study Peckham was being touted in the property pages of the newspapers as an 'up and coming' neighbourhood. The increasing property prices were concurrent with shifts within the consumption infrastructure-bars, coffee shops, retail facilities for artisan goods-that continue to this day. The retail transformation of Peckham is central to the council's redevelopment plans that stress the need for more cafes and restaurants 'as if the economic and cultural diversity ... as it exists was somehow invisible to those undertaking the planning exercise' (Hall, 2015, 23). While Peckham remains intensely multicultural, the area is being restructured along racialised and classed lines. Since conducting the research Peckham's position in the London art world and as a destination and place of residence for the young middle classes have been further consolidated; property prices, both for purchase and rental have risen further. At the time of research the average price for a property in SE15 was $£ 268,296$ (2010), while at the time of writing it is $£ 390,835$ (Land Registry, 2015). This is a 45.7 per cent increase in price over 5 years.

The area we chose within Peckham-selected because of its appearance as a gentrifying area-loosely corresponds to the 'Bellenden Improvement Zone', a council-led renewal scheme that included grants for the improvement of house exteriors and the commissioning of new street furniture from its local resident artists. However, middleclass presence in Peckham predates this scheme. Our research identifies a wave of middle-class people moving to this area in the 1970s and 1980s, including a number of artists and architects, as is often the case in gentrifying areas. This generation's 
upgrading of their properties over time mirrors the kinds of changes that Ruth Glass (1964) observed in Islington.

This neighbourhood is defined by its proximity to the high street, Bellenden Road, and a dominant middle-class presence. It is located in the Lanes Ward, which includes this area. 34.7 per cent of those employed are classified as managers and senior officials, or professional. A further 18.5 per cent classified as associate professional and technical, higher than average for England and Wales. The neighbourhood also has a higher percentage of white residents (60.4 per cent) than the Southwark average (54.2 per cent).

While other neighbourhoods in the study were more homogeneously middle class and home to majority owner-occupiers, tenure in this area was more mixed; it was a neighbourhood popular with young adults, as well as long-term middle-class residents and young families. At ward level, 45 per cent of properties were owned or shared ownership, 23.5 per cent privately rented, and 31.4 per cent socially rented. Our study identified younger people moving into the area for a range of reasons that included, its then burgeoning art scene, its proximity to East Dulwich, and cheaper housing costs.

In this area of Peckham we can observe a set of overlapping and interconnected changes unfolding in terms of the population and the built environment. A slower process of gentrification through the upgrading of houses taking place alongside more rapid changes brought about by the changes to the transportation infrastructure and the 'pop up' style interventions of a group of young artistic/entrepreneurial people. Such transformation reflect wider changes in Peckham; they structure social divisions in the 
area and raise urgent questions about social and ethnic mix, class and the politics of place which are the focus of our separate but ongoing research in the area.

The mix of tenure and age among the Peckham residents who took part in the research, and the rapid urban transformation of the area, gives us the opportunity to examine how mixed feelings and decisions made about property ownership, residential choice and neighbourhood change, are expressed by variously positioned middle-class subjects with the same (changing) place.

\section{Heightened Anxieties: Social Reproduction and Housing}

Property ownership and place of residence have become crucial identifiers within middle-class identity-making practices (Savage et al. 2005), but the question remains: for whom? In the London context, the 'Baby Boomers' who accrued housing assets over a lifetime of home ownership that coincided with the increasing privatization and valuation of housing in the capital were a product of their time. Notwithstanding the significant variation in experience and social mobility even within this generation, we start from the position of arguing that within research on the middle classes, this figuration has particular prominence and has come to serve as a measure by which we understand the middle classes.

Across the London neighbourhoods in the study, older generations of middle-class people repeatedly voiced concerns to us about their children's housing prospects; in contrast, we found little corresponding concern about their children's employment prospects, despite the context of economic upheaval and labour market uncertainty affecting private and public sectors. The timbre of these interviews, and in particular 
the uncertainties and anxieties of many of our respondents suggests that changes are afoot within London's middle classes; the terms by which the middle classes define themselves are shifting in relation to housing.

The significance of home-ownership in class reproduction is twofold. First, because of its potential as a store or source of wealth, it is possible transmit this wealth to children or other beneficiaries in the form of housing inheritance. Secondly, it can be argued that, if the parents own, this may help engender a "culture of ownership" (Hamnett 1995: 269).

Concerns were raised over children being able to afford housing in 'desirable' locations, while younger respondents reflected on their difficulties in their experiences of renting in the capital and in the future getting a foot on the housing ladder. The structural constraints that many of the younger respondents experienced were evident in their discussions of their housing futures:

I'm trying to save for a deposit and there's no interest rates ... which is a bit frustrating, particularly when you read all these stories about the average age of first time buyers going up, and without help from here, there and everywhere you're not going to buy one until you're 58 or whatever... And there is such a huge disparity between London prices and outside ... I knew I wanted to work for a charity therefore never expected to earn much more than ... I remember thinking at university I doubt I'll earn more than 30 grand a year. But then expectations change when you realise how expensive houses are and what jobs pay, and what have you. (Charlotte) 
These frustrations show how shifting housing economies are reflected in shifting expectations. Charlotte pursued the career of her choice, in full knowledge that earnings were relatively low but now realizes that this holds her back in the London housing market. Notably, she makes comparisons to outside London, where getting onto the housing ladder is viewed as considerably easier.

What might this mean for the future of a generation who were raised into a 'culture of home-ownership' (Hamnett 1995) and who are finding it difficult to access housing in places where they might originally have anticipated? Sylvia, a woman in her 60s reflected on this very clearly in her interview:

... certainly as things are progressing, you could well have very well-educated people who have had good earning potential ... who then lose that and are then going to be more dependent upon, either benefits, or having a much lower standard of living, in terms of where they live and how they live.

The premise of first wave gentrification precisely relates to such circumstances - the middle classes, unable to find homes in desirable areas but wanting to enter into property ownership, buying in less desirable locations and displacing local populations (Glass 1974; Butler and Robson 2003). However, there is an ever-decreasing pool of areas where those on even medium incomes can afford to buy or rent the housing that they need. This is telling, not only in relation to how the middle classes negotiate the London housing market, but also of changing relations of class and space within the city, 
where certain portions of those who by occupational and income measures would be categorised as middle class struggle to maintain a stake in the field of housing.

Of course, this is not the whole picture. Inheritance and housing equity release by parents may be an important dimension of this. As Hamnett and Seavers (1994) stress, class alone does not determine how assets are passed on (or not) through inheritance (other aspects might include the number of children in the family, where the property is in the country and what type of property it is, divorce, age of parents at death, inheritance tax). The accrual of housing wealth and assets by previous generations might facilitate the access to home ownership of a younger generation but this is by no means assured given current changes to welfare and healthcare. Similarly, disruptions to housing trajectories-redundancy, divorce, changing economic circumstancesmight have adverse effects on access to housing. What remains clear in our data is that there are generational differences in the fortunes and aspirations of the middle classes.

\section{Ambivalence: Reluctant winners and stressed renters}

While holding different stakes in relation to housing, both the 'pioneer gentrifiers' and young renters of Peckham described valuing the artistic and creativity of Peckham alongside social and ethnic mix. This left them with ambivalent feelings about the ongoing gentrification of the area.

The quotation below demonstrates the mixed feelings of the older generationincluding left-leaning people and those working in professions such as architecture, housing, law and psychotherapy—who had bought in the area in the 1970s and 1980s. 
The housing wealth that they had accrued was substantial in comparison to their earnings, and led to expressions of ambivalence about their role and position within the housing market.

Moira: I suppose you could say the street is getting more gentrified ... there's a lot of slow doing up of houses ... it's a real problem in the sense that the house has tripled in value since I bought it. So it's a problem for what kind of people can live here.

Emma: And your reaction, you said that it's a bit of a 'problem'... do you feel like it's a bit of a problem or is it something that...

Moira: I suppose I take a fairly political view of these things, where working class people get priced out of an area ... it's... the sort of place now that people would want to send their sons or daughters to a private school but can't really afford to, they will buy a place here so that their kids can then cycle or they can drive them to school ... I think the massive increase in house prices has had a disastrous affect on people's access to housing. That's absolutely clear. And when I say people's access to houses, those who have no choice in the matter. Where they are stuck in poor quality housing. They get priced out of the market. They've been priced out of the area. Rents go up, house prices go up too.

Emma: But I suppose in a way you've -

Moira: I'm part of the problem.

Emma: I wasn't going to say that

Moira: Of course I am, I can see that. 
Aged in her sixties and resident in the area for ten years, Moira was typical of these older residents in expressing a strong attachment to the area; she was all too aware of how she had benefitted from gentrification in Peckham, having 'upgraded' from a different property ten years earlier.

Further elements of such narratives were concerns about working-class people being pushed out; feeling ill at ease with wider neighbourhood changes, fear of homogenisation and expensive shops moving in. But this is paired with the acknowledgment that they have benefitted financially and, from a political and economic point of view, are 'part of the problem'. The awkwardness of this interview encounter and Moira's presumption that the interviewer is judging her in some way reflects this ambivalent position. Furthermore, the recognition of the compromises (Bridge 2003; Bacqué et al 2014; Reay et al. 2011) that people moving into the neighbourhood were making locates her position as part of a wider trajectory of change. Nevertheless, such older middle-class residents were positioned very differently in terms of housing assets to more recent incomers, young renters, who made up almost a quarter of the Peckham sample, and who often narrated a very different stake in the neighbourhood. For many of these households, renting in Peckham was not just about affordability but also what they thought the area offered to them, particularly the arty, bohemian feel of the neighbourhood.

Isabella had stayed in the neighbourhood following graduation from Camberwell College of Arts, despite increasing rents, because she felt part of the local art scene. Frida, a university administrator, spent most of her income on rent because of the 'beauty and tranquility' of her street, which she starkly contrasted with other rental 
properties in the area: 'I was actually appalled at what was being offered to people, as accommodation, as a home'. The accounts of these renters foreground the pressures of the rental market and present different interrelationships between the pushes and pulls of the cost of rent and the developing of an affinity for a certain corner of South East London.

Isabella and her boyfriend Jack were in their 20s. When asked to describe their class position they drew on their private school backgrounds to articulate being middle class, but at the same time expressed uncertainty about what the future may hold, 'I don't think we're going to end up there. In terms of what our parents did for us'. Embroiled in the local art scene, they describe themselves as part of a community of, 'students [that] have now graduated and are still kind of hanging on ... '. They planned to stay in the local area for the foreseeable future, although voicing vague intentions to leave London after 10 years. Their accounts demonstrate how they are positioned as renters within a fast-changing housing economy:

Isabella: ... the landlord, or the estate agent, put up our rent this year which Jack: $\quad$ Oh yeah and we managed to get it down a bit ...

Isabella: $\quad$... quite a lot of money more. And we sort of said no. But they had quite a powerful argument because they were saying, oh well your flat's worth three hundred pounds more than it was last year

They managed to get the rent increase slightly reduced; 'sort of' saying no, indicating a particular deployment of confidence, while also accepting the logic of the landlord's 'powerful argument' that the flat is simply worth more money now. 
For older renters such as Emily (30s), struggles within the rental economy translated to rethinking her position within the middle classes:

I think I feel generally poorer than ... most ... people. Not most people because I know obviously there are people [...] a lot more ... my boyfriend works freelance and I'm a nurse in the NHS, so I feel that I have less disposable income than the average middle-class person in London ... I don't imagine that I would be capable of buying a house here ... so overall I feel like I probably have to struggle a bit more to ... generally live.

This struggle leads Emily to imagine a future elsewhere, describing living in London as 'hard work'. Underpinning this is an understanding of London housing as a field, its geographical dimensions influencing how class is articulated.

Those who occupy ambivalent positions in relation to the ongoing gentrification of the neighbourhood articulate a range of responses. For the older generation of homeowners, the refusal to make use of the exchange-value of their property-at least for now-can be understood as one strategy for managing their ambivalence for what has happened within the neighbourhood as it manifests in increased property prices. The decision to stay put is an active choice. Younger renters who are 'hanging on' have to strategise to stay where they are and deploy resources to this end (as in the above example, by negotiating with the landlord) because the neighbourhood is valuable in terms of the cultural life it offers them. However, for some such as Emily, one solution to the challenge of living in London is to leave. 


\section{Consolidators: Investment, compromise and class}

Among middle-class owner-occupiers in their thirties, another narrative emerged that highlighted their compromises in relation to location: Peckham as an investment. In order to get housing they can afford within the changing London housing market such narratives describe how they selected neighbourhoods that they would not have considered in other circumstances. By buying in Peckham they were consolidating their class position through housing tenure though not on 'solid' middle class territory (Bacqué et al. 2014).

Actually, the primary reason [for buying a flat in Peckham] was investment purposes because, I wanted to invest some money in buying a property, money that was left to me in inheritance and so I was reading an article in The Sunday Telegraph property section and it listed, in their opinions, the country's top places to invest in property for long term equity and Peckham was number one on the list. It was about $2006 \ldots$ the next one in London was Acton, so I spent a day walking around Peckham, and another day walking around Acton, and I much preferred Peckham and I thought I could see myself living here and then everything else fell into place ... originally it was purely the investment. (Richard)

Richard was particularly straightforward in his account of investing in Peckham for financial reasons but was also effusive about the area, prizing its independent spirit and quirkiness.

... you only have to chat to people like in the chocolate shop or the book shop and you'd find out about all this stuff that's going on and all this weird and wonderful stuff that happens here, and people fall in love with it ... In a way I hope they do 
because it means the property prices go up which means this place would be worth more, and I'll be able to sell it and make lots of money, but at the same time, it might lose that kind of feel to it.

While the decision to live there was initially made on the grounds of investment, Richard describes a process of becoming embedded in the area. He volunteered locally and said he was socialising more and more within the neighbourhood.

Annette and her husband had moved to Peckham from Battersea in 2001, where she had been renting. They had chosen southeast London over southwest because of the substantially cheaper property costs. After looking in Dulwich and Peckham, they were faced with a choice:

I would say between 2001 and 2007 the prices really rocketed in Dulwich and then suddenly became a very trendy area ... it was always that choice, you pay a little bit more and live just off Lordship Lane [East Dulwich], or do you live in Peckham a little bit less pricey but you walk a little bit further to get to the bar. So, at the end obviously we decided to go to Peckham because we prefer to have more space.

For Annette moving to Peckham was a financial decision based on the trade off outlined above and anticipation, 'you could feel that something was going to change, there were more and more young people living there.' The proximity to Lordship Lane brought the promise of that area's consumption infrastructure spilling over. For Annette, this move was a stepping-stone. From the outset they had planned to leave Peckham, realising this finally in 2010.

For this group, hopes for property investment coming to fruition and their navigation of the housing market paying off were expressed alongside some concern about 
gentrification. However, this concern is not couched in terms of displacement of working-class residents as with the first group but with a loss of the independent spirit that they perceive as characterising their part of Peckham. In contrast to the groups discussed in the previous section, these respondents move to Peckham and invest in property precisely to consolidate their middle-class positions.

\section{Conclusion}

This paper has shown that the current conditions of the housing economy are felt and responded to by London's middle classes in a variety of ways. We highlight this here not to add to concerns about the 'squeezed middle' but rather because we think this is significant for understanding how changing economic and social processes generate new classed practices and formations. Rather than simply state these as evidence of the further fragmentation of the middle classes within neoliberal economies, we consider what this reveals about the project of middle-class identity formation. The changing stakes of the middle classes within London's housing markets points to the exacerbation of housing inequality among the middle classes and the significance of tenure within this. Even within the middle classes, it is clear that some people are just trying to make ends meet, part of which might include 'hanging on' in a place where they do not have to commute too far to get to work. Such conditions make clear that for some sections of the middle classes, staying in place and staying middle class takes work.

The heightened anxieties around housing middle-class young people, captured so well by the popular media and echoed repeatedly by the middle-class parents within the 
project, provide a significant foundation for the re-evaluation of the relationship between housing and class. Located within a broader political economy, it is pertinent to question what work such narratives do. We argue that they are critical in paving the way for value to be claimed for actions that might otherwise seem at odds with a middle-class housing trajectory. Attendant ambivalence about the profits made off the back of (pioneer) gentrification similarly figure in this foundational work, while also demonstrating a desire of some middle-class subjects to appear ordinary (Savage et al. 2001), despite recognising their privileged position, at least in relation to their accumulated housing assets.

In addition, we have identified two very different coping strategies among the younger respondents in Peckham. The 'investors' seek to slowly manoeuvre a way into a 'proper' middle-class position, through using a cheaper neighbourhood as a stepping-stone in the property market or through valorising their locality and making it a place for 'people like us' (see also Benson and Jackson, 2013). Meanwhile, the renters express a keen sense of disadvantage within the property market but frame this situation as exceptional (in regards to place and time). While recent research on the middle classes in Britain has focussed heavily on the role of place in middle-class identity formation, a focus on young middle-class renters in London reveals how staying in place takes work. Through a series of manoeuvres, including strategizing to stay in a neighbourhood that has (sub)cultural value, or through a strategy of moving to a neighbourhood where being middle class is possible, these young subjects seek to preserve their middle-class status. This strategizing within the constraints of the London housing markets has its limits, however, and for some, like Emily, the only likely solution is an exit. 
Within the context of London's hyper-inflated housing economy, the middle classes salvage symbolic value from the conditions that-within the dominant categorizations of the middle classes-might otherwise position them as lacking in value. Through this lens, the middle classes, rather than being in crisis are actively being remade, albeit on shifting ground.

\section{Notes}

1. The final iteration of this paper took place just shortly after the 2016 referendum on the United Kingdom's continued membership of the European Union. It is uncertain what impact the decision to leave the European Union will have on property prices in London.

2. Unless otherwise stated, all statistics reported in this section have been calculated from Census 2011, found at the Office For National Statistics, NOMIS website (http://www.nomisweb.co.uk).

\section{Acknowledgements}

The research reported in this paper was part of the project The Middle Classes in the City funded by the Economic and Social Research Council (ESRC RES-062-33-0002). We would also like to thank Professor Gary Bridge (PI), Professor Tim Butler (Co-I) for their support over the course of the research and the writing of this paper.

\section{References}

Allen, K. and Roberts, S. 2016 'Millenials v Baby Boomers: A battle we could have done without', The Conversation, $6^{\text {th }}$ April 2016 [http://theconversation.com/millennials-vbaby-boomers-a-battle-we-could-have-done-without-57305]

Atkinson, W. 2015 Class, Cambridge: Polity Press. 
Atkinson, W., Savage, M., and Roberts, S. 2012 'Introduction: A Critical Sociology of the Age of Austerity', in W. Atkinson, S. Roberts \& M. Savage (eds), Class Inequality in Austerity Britain: Power, Difference and Suffering. Palgrave Macmillan.

Bacqué, M-H., Bridge, G., Benson, M., Butler, T., Charmes, E., Fijalkow, Y., Jackson, E., Launay, L., and Vermeesch, S. 2015 The Middle Classes and the City: A Study of Paris and London, London: Palgrave.

Bacqué, M-H., Charmes, E., and Vermeesch, S. 2014 'The Middle Class 'At Home Among the Poor' - How Social Mix is Lived in Parisian Suburbs: Between Local Attachment and Metropolitan Practices', International Journal of Urban Research 38(4): 1211-1233.

Barker, K. 2004 The Barker Review of Housing Supply. London: HM Treasury.

Barker, K. 2014 Housing: Where's the Plan? London: London Publishing Partnership.

Benson, M. 2014 'Trajectories of Middle-Class Belonging: The Dynamics of Place Attachment and Classed Identities', Urban Studies 51(14): 3097-3112.

Benson, M. and Jackson, E. 2013 'Place-making and Place Maintenance: Performativity, Place and Belonging Among the Middle Classes', Sociology 47(4): 793-809.

Bone, J. and O'Reilly, K. 2010 'No Place Called Home: The Causes and Social Consequences of the UK Housing 'Bubble”, The British Journal of Sociology 61(2): 231255.

Bourdieu, P. 1984 Distinction, London: Routledge.

Bradley, H. 1995 Fractured Identities: Changing Patterns of Inequality, Cambridge: Polity Press.

Bradley, H. 2014 'Class Descriptors or Class Relations? Thoughts Towards a Critique of Savage et al.', Sociology 48(3): 429-436. 
Bridge, G. 2003 'Time-Space Trajectories in Provincial Gentrification', Urban Studies 40(12): 2545-2556.

Burrows, R., Webber, R. and Atkinson, R. (In press) 'Welcome to Pikettyville? The Geodemographics of the "Super-Rich" in London', The Sociological Review.

Butler, J. 1990 Gender Trouble, London: Routledge.

Butler, J. 1993 Bodies that Matter: On the Discursive Limits of Sex, London: Routledge.

Butler, T. and Robson, G. 2003 London Calling: The Middle Classes and the Remaking of Inner London, London: Berg.

Chauvel, L. 2006 Les Classes Moyennes à la Dérive, Paris: Editions de Seuil.

Crompton, R. 2008 Class and Stratification, Cambridger: Polity.

Dorling, D. 2014 'Thinking about Class', Sociology 48(3): 452-462.

Dorling, D. 2015 All That is Solid. London: Penguin.

Ehrenreich, B. 1990 Fear of Falling: The Inner Life of the Middle Class. New York: Harper Perennial.

Forrest, R. and Murie, A. 1980 'Wealth, Inheritance and Housing Policy', Policy and Politics 8(1): 1-19.

Forrest, R., Murie, A. and Williams, P. 1990 Home Ownership: Differentiation and Fragmentation, London: Unwin Hyman.

Glass, R. 1964 London: aspects of change, London: MacGibbon \& Kee.

Gordon, B. 2014 'Kirsty Allsopp: 'Women Should Put Off University to Find a 'Nice Boyfriend' and Have Babies', The Telegraph 2 June 2014: npg.

Goux, D. and Maurin, E. 2012 Les Nouvelles Classes Moyennes, Paris: Seuil.

Greater London Authority 2008 Credit Crunch and the Property Market, London: Greater London Authority. 
Greater London Authority 2014 Housing in London 2014: The Evidence Base for the Mayor's Housing Strategy, London: Greater London Authority.

Hamnett, C. 1995 Home-Ownership and the Middle Classes, in T. Butler and M. Savage (eds) Social Change and the Middle Classes, London: UCL Press.

Hamnett, C. 1998 Winners and Losers. Home Ownership in Modern Britain, London: Routledge.

Hamnett, C. and Seavers, J. 1994 A step on the ladder: home ownership careers in the South East, The South East Programme, OP15, The Open University.

Jackson, E. and Benson, M. 2014 'Neither 'Deepest, Darkest Peckham' nor 'Run-of-theMill' East Dulwich: The Middle Classes and their 'Others' in an Inner London Neighbourhood', International Journal of Urban and Regional Research 38(4): 11951210.

Kennett, P., Forrest, R. \& Marsh, A. 2013 'The global economic crisis and the reshaping of housing opportunities', Housing, Theory and Society 30(1): 10-28.

Land Registry 2015 House Price Index April 2015. Available at https://www.gov.uk/government/uploads/system/uploads/attachment_data/file/430 497/HPIReport20150511.pdf. Accessed 22nd June 2015.

Marshall, L. and Smith, N. 2016 First-Time. An Early Life Crisis: Britain's Homeownership Aspirations. Yorkshire: Yorkshire Building Society.

Maurin, E. (2009) La Peur de Declassement, Paris: Editions de Seuil.

McKee, K. \& Muir, J. 2013 'An Introduction to the Special Issue--Housing in Hard times: Marginality, Inequality and Class', Housing, Theory and Society, 30(1): 1-9.

McKee, K. 2012 'Young People, Homeownership and Future Welfare', Housing Studies 27(6): 853-862. 
Office for National Statistics 20152011 Census: Home Ownership Down and Renting Up for the First Time in a Century, Available online at: http://visual.ons.gov.uk/housingcensus/.

Pennington, J., Ben-Galim, D., and Cooke, G. 2012 No Place to Call Home: The Social Impacts of Housing Undersupply on Young People, London: IPPR.

Reay, D., Crozier, G., and James, D. 2011 White Middle Class Identities and Urban Schooling, Basingstoke: Palgrave Macmillan.

Saunders, P. 1978 'Domestic Property and Social Class', International Journal of Urban and Regional Research 2: 233-251.

Saunders, P. 1990 A Nation of Homeowners, London: Unwin Hyman.

Savage, M. 2015 Social Class in the $21^{\text {st }}$ Century, London: Penguin Books.

Savage, M. and Butler, T. 1995 'Assets and the Middle Classes in Contemporary Britain', in T. Butler and M. Savage (eds) Social Change and the Middle Classes, London: UCL Press.

Savage, M., Bagnall, G., and Longhurst, B. 2001 'Ordinary, Ambivalent and Defensive: Class Identities in the Northwest of England', Sociology 35(4): 875-892.

Savage, M., Barlow, J., Dickens, P. and Fielding, T. 1992 Property, Bureaucracy and Culture: Middle-Class Formation in Contemporary Britain. London: Routledge.

Savage, M., Devine, F., Cunningham, N., Taylor, M., Li, Y., Hjellbrekke, J., Le Rouz, B., Friedman, S., and Miles, A. 2013 'A New Model of Social Class? Findings from the BBC's Great British Class Survey Experiment', Sociology 47(2): 219-250.

Savage. M., Devine, F., Cunningham, N., Friedman, S., Laurison, D., Miles, A., Snee, H. \& Taylor, M. 2015 'On Social Class, Anno 2014', Sociology 49(6): 1011-30.

Skeggs, B. 1997 Formations of Class and Gender, London: SAGE.

Skeggs, B. 2004 Class, Self, Culture, London: Routledge. 
Skeggs, B. 2015 'Introduction: Stratification or Exploitation, Domination, Dispossession and Devaluation', The Sociological Review 63(2): 205-222.

Sprigings, N. 2008 'Buy-to-let and the Wider Housing Market', People, Place and Policy Online.

Timita, M. (2014) House Prices in England: The Long-Run Growth, Illustreets [Available at: http://illustreets.co.uk/blog/maps-and-apps/house-prices-in-england-the-long-rungrowth/; last accessed 25 ${ }^{\text {th }}$ April 2016]

Tyler, I. 2015 'Classificatory Struggles: Class, Culture and Inequality in Neoliberal Times', The Sociological Review 63(2): 493-511.

Wacquant, L. 1991 'Making Class: the Middle-Class(es) in Social Theory and Social Structure', in S. McNall, R. Levine, and R. Fantasia (eds) Bringing Class Back in: Contemporary Historical Perspectives, Boulder, CO: Westview Press.

Watt, P. 2005 'Housing Histories and Fragmented Middle-class Careers: The Case of Marginal Professionals in London Council Housing', Housing Studies 20(3): 359-381. 